\title{
Effects and Safety of an Oral Adsorbent on Chronic Kidney Disease Progression: A Systematic Review and Meta-Analysis
}

Ying-Chun Chen ${ }^{1,+}$, Mei-Yi Wu ${ }^{2,3,4,5,+}{ }^{\mathbb{D}}$, Ping-Jen Hu ${ }^{6,7}$, Tzu-Ting Chen ${ }^{4,5}$, Wan-Chen Shen ${ }^{1}$, Wei-Chiao Chang ${ }^{8,9,10,11, *}$ and Mai-Szu Wu ${ }^{2,3, *}$

1 Department of Pharmacy, Shuang Ho Hospital, Taipei Medical University, New Taipei City 23561, Taiwan; 12556@s.tmu.edu.tw (Y.-C.C.); 16323@s.tmu.edu.tw (W.-C.S.)

2 Division of Nephrology, Department of Internal Medicine, School of Medicine, College of Medicine, Taipei Medical University, Taipei 11031, Taiwan; e220121@gmail.com

3 Division of Nephrology, Department of Internal Medicine, Shuang Ho Hospital, Taipei Medical University, New Taipei City 23561, Taiwan

4 Institute of Epidemiology and Preventive Medicine, College of Public Health, National Taiwan University, Taipei 10617, Taiwan; uniquepapa@gmail.com

5 Department of Primary Care Medicine, Shuang Ho Hospital, Taipei Medical University, New Taipei City 23561, Taiwan

6 Division of Gastroenterology and Hepatology, Department of Internal Medicine, Taitung MacKay Memorial Hospital, Taitung 95054, Taiwan; a801891@hotmail.com

7 Division of Gastroenterology, Department of Internal Medicine, Shuang Ho Hospital, Taipei Medical University, New Taipei City 23561, Taiwan

8 Master Program in Clinical Pharmacogenomics and Pharmacoproteomics, School of Pharmacy, Taipei Medical University, Taipei 11031, Taiwan

9 Department of Clinical Pharmacy, School of Pharmacy, Taipei Medical University, Taipei 11031, Taiwan

10 Integrative Research Center for Critical Care, Wan Fang Hospital, Taipei Medical University, Taipei 11696, Taiwan

11 Department of Medical Research, Shuang Ho Hospital, Taipei Medical University, New Taipei City 23561, Taiwan

* Correspondence: wcc@tmu.edu.tw (W.-C.C.); maiszuwu@gmail.com (M.-S.W.)

+ Ying-Chun Chen and Mei-Yi Wu contributed equally.

Received: 23 September 2019; Accepted: 14 October 2019; Published: 17 October 2019

\begin{abstract}
Background: AST-120 (Kremezin), which is an oral spherical carbon adsorbent, has been reported to have the potential for retarding disease progression in patients with chronic kidney disease. We aimed to evaluate its efficacy and safety in this study. Methods: We systematically searched for randomized controlled trials published in PubMed, Embase, and Cochrane databases. The primary outcomes were the renal outcome and all-cause mortality, and the change in serum indoxyl sulfate (IS) levels. The safety outcome was also evaluated in terms of reported major adverse events. A random-effects model was used when heterogeneity was expected. Results: Eight studies providing data for 3349 patients were included in the meta-analysis. The risk ratio of renal outcome and all-cause mortality were 0.97 (95\% CI: $0.88-1.07 ; 6$ trials) and 0.94 (0.73-1.20; 5 trials), respectively. Furthermore, the weighted mean change in IS levels from baseline to the end of the study was $-0.28 \mathrm{mg} / \mathrm{dL}$ (95\% CI: -0.46 to $-0.11 ; 4$ trials). Conclusions: This study provides evidence that AST-120 can effectively lower IS levels but still controversial in terms of slowing disease progression and all-cause mortality. Except for dermatological events, the incidence of adverse events did not differ significantly between the AST-120 and placebo groups.
\end{abstract}

Keywords: AST-120; Kremezin; chronic kidney disease; systematic review; meta-analysis 


\section{Introduction}

Chronic kidney disease (CKD) is a global health concern [1] where many patients with the disease advance to end-stage renal disease (ESRD), which requires dialysis or kidney transplantation, increases mortality, and reduces quality of life [1,2]. According to one estimate, by 2030, patients with ESRD will account for 5.4 million people on dialysis [3], making early management of CKD and its risk factors a crucial clinical concern. Current guidelines for the management of CKD focus on controlling factors that can accelerate CKD progression, such as hypertension and diabetes $[4,5]$.

AST-120 is an orally administered adsorbent, which consists of spherical particles $0.2-0.4$ $\mathrm{mm}$ in diameter. It is predominantly composed of carbon [6] and can adsorb uremic toxins and precursors, such as indoxyl sulfate (IS), causing their subsequent excretion in feces [6,7]. AST-120 was shown to suppress oxidative stress in uremic rats [8] and has been reported to effectively slow the progression of glomerular sclerosis, tubulointerstitial fibrosis, and proximal tubular hypertrophy $[9,10]$. As a pharmaceutical agent, AST-120 was first approved in Japan in 1991 to alleviate uremic symptoms and delay the need for dialysis in patients with CKD [6]. It was later approved in Korea, Taiwan, and the Philippines for treating CKD patients.

Over the past two decades, the effects of AST-120 have been evaluated in patients with CKD in many prospective clinical trials and retrospective studies. However, the renoprotective effects of AST-120 are still relatively unknown. Furthermore, it is also unclear whether current evidence supports the recommended use of AST-120 in CKD patients. In the present study, we evaluated AST-120's safety and efficacy in retarding CKD progression. To do so, we conducted a systematic review and meta-analysis of published literature with a preplanned study protocol, well-designed search strategy, and a critical assessment of comprehensive studies.

\section{Materials and Methods}

\subsection{Search Strategy and Selection Criteria}

We searched the Pubmed, Embase, and Cochrane CENTRAL databases from their inception dates up to 31 July 2018 using the free-text key words, MeSH terms, or Emtree terms: "AST-120" or "Kremezin" and "chronic kidney disease." Unpublished studies were searched on ClinicalTrials.gov, and the references cited in the selected studies were reviewed to obtain additional relevant literature. The investigators reviewed the titles and abstracts of the retrieved studies to exclude duplicate studies, irrelevant studies, and studies that did not meet the eligibility criteria. The full text of potentially relevant studies was carefully reviewed, and the studies were included if: (1) patients with stages 3-5 CKD were enrolled, (2) the effects of AST-120 were evaluated, (3) patients were randomized into a group receiving AST-120 and another receiving a placebo or conventional treatment in the trial, and (4) one or more primary or secondary outcomes were reported. A study was excluded if it: (1) did not report outcomes of interest clearly, (2) did not provide sufficient information to extract or calculate treatment effects, (3) was not a randomized controlled trial (RCT), or (4) evaluated the same or overlapping patient cohorts as one or more other studies. Our systematic review has been accepted by PROSPERO, an online international prospective register of systematic reviews, which is funded by the National Institute for Health Research (CRD42019136927).

\subsection{Primary and Secondary Outcomes}

The primary outcomes were a composite of renal outcomes, all-cause mortality, and the change in serum IS levels. The composite of renal outcomes comprised the doubling of serum creatinine levels, increase in serum creatinine levels to $\geq 6.0 \mathrm{mg} / \mathrm{dL}, 50 \%$ reduction in estimated glomerular filtration rate (eGFR), initiation of dialysis, and initiation of kidney transplantation. Safety of AST-120 was evaluated using the risk of constipation, diarrhea, gastrointestinal disorders, and dermatological events. 


\subsection{Data Extraction and Risk of Bias Assessment}

Two investigators (Mei-Yi Wu and Ying-Chun Chen) independently reviewed the included trials and extracted relevant data. After eliminating duplicate records, the two investigators independently examined the titles and abstracts to exclude clearly irrelevant studies. Next, the investigators independently retrieved and examined full texts of potentially relevant studies to determine whether the studies met the inclusion criteria. The investigators made a final decision regarding the inclusion of eligible studies and extracted information, including the name of the first author, publication year, country, study design, number of total patients and number in each arm, experimental drugs administered, population, age, duration of follow-up, baseline serum creatinine levels, composite of renal outcomes, all-cause mortality, change in serum IS levels, constipation, diarrhea, gastrointestinal disorders, and dermatological events. Because the mean change in serum IS levels from baseline was unavailable for each patient, the mean change in the IS levels in each treatment was calculated by subtracting the final mean from the baseline mean. When the standard deviation of the change from baseline in each treatment was not available, we estimated the missing standard deviation by using an imputed value for measures with a correlation coefficient of 0.5 . Moreover, two reviewers independently assessed the risk of bias, including the selection bias, performance bias, detection bias, attrition bias, reporting bias, and other bias, by using the Cochrane risk of bias tool for randomized trials [11].

\subsection{Data Synthesis and Analysis}

The weighted mean difference for the change in serum IS levels and risk ratios (RRs) for the composite of renal outcomes, all-cause mortality, and adverse effects among different treatments were calculated. A fixed-effect model with a common treatment effect and a random-effects model with a heterogeneous treatment effect across studies were used. Pooled estimates of the weighted mean difference were computed using the Mantel-Haenszel test and estimates of RRs were made with the inverse variance method. The precision of effect sizes was estimated using $95 \%$ confidence intervals (CIs). Statistical heterogeneity was assessed using the $\mathrm{I}^{2}$ statistic, with $\mathrm{I}^{2}$ values of $>50 \%$ indicating substantial heterogeneity [12]. Funnel plots were used to determine publication bias regarding the end points. In this study, zero correlation was assumed between the change-from-baseline outcome measures when paired analyses were not available [13]. Moreover, sensitivity analysis was conducted to resolve the issue of synthesizing data from crossover trials into meta-analyses. All statistical analyses were performed using the statistical package, Review Manager, version 5.3 (Cochrane Collaboration, Oxford, England).

\section{Results}

\subsection{Subsection}

\subsubsection{Study Characteristics}

In our analysis, we included eight studies that included a total of nine RCTs [14-21]. A flowchart summarizing the screening and selection process for the studies is shown in Figure 1. Our initial search strategy yielded 324 citations, but 129 were excluded as duplicate records. One hundred and thirty citations were excluded after screening the titles and abstracts. We then retrieved the full texts of 65 studies. Of these 65, we excluded studies that were not RCTs, studies that did not have a control group, and those in which the population, intervention, and outcomes did not meet the requirements of our meta-analysis. Finally, we included eight studies with nine RCTs in our analysis. The nine RCTs were published between 1997 and 2016 and had sample sizes ranging from 26 to 1007; the total number of participants across the studies was 3349 (Table 1). All RCTs recruited patients with stage 3-5 CKD, and the mean patient ages ranged from 54.4 to 69.3 years. The AST-120 dosages, ranging from 2.7 to $9 \mathrm{~g} /$ day, were adjusted according to various protocols. The follow-up lengths in the included 
trials ranged from 7 days to 3 years. Serum creatinine levels at baseline varied widely across studies, ranging from 2.36 to $5.75 \mathrm{mg} / \mathrm{dL}$.

324 records identified by searching

PubMed, Embase, Cochrane Central

databases, and ClinicalTrials.gov

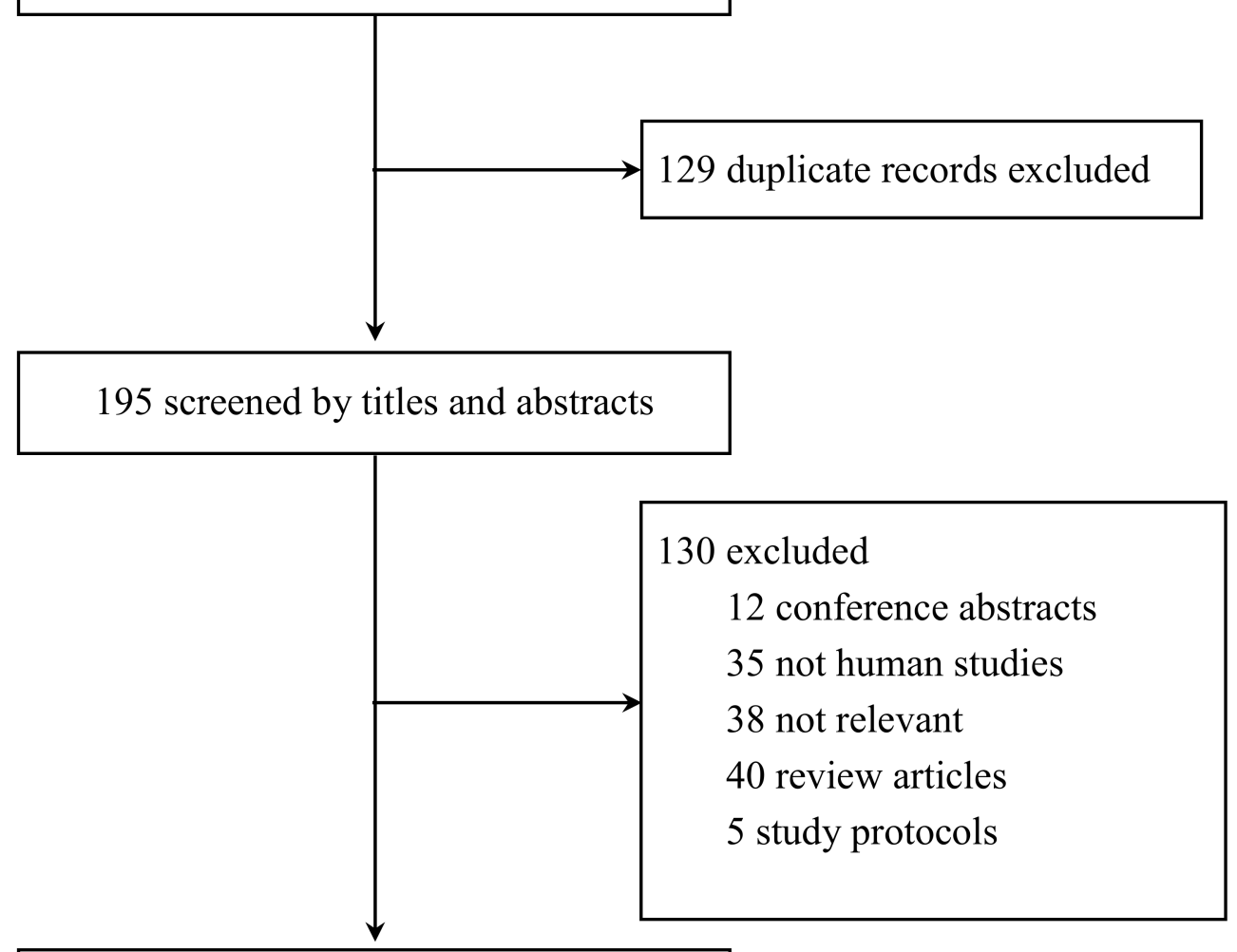

65 full-text articles assessed for eligibility

\section{6 excluded}

7 unsuitable population

5 unsuitable intervention/comparison

11 unsuitable outcomes

24 unsuitable study type

10 without control group

8 studies included in the meta-analysis

Figure 1. Flowchart of the literature search and trial selection. 
Table 1. Characteristics of included studies.

\begin{tabular}{|c|c|c|c|c|c|c|c|}
\hline Study & Country/Region & Population & Intervention/Comparison & Duration & $\begin{array}{l}\text { No. of Patients } \\
\text { (\% of male) }\end{array}$ & Age & Baseline sCr \\
\hline \multirow{2}{*}{ Akizawa 2009 [14] } & \multirow{2}{*}{ Japan } & \multirow{2}{*}{ CKD stages $3-5$} & I: AST-120 6 g/day & \multirow{2}{*}{56 weeks } & I: $231(34.6)$ & I: $62.9 \pm 13$ & I: $2.66 \pm 1.03$ \\
\hline & & & C: LPD and RASi & & C: 229 (31.9) & $C: 63.3 \pm 11$ & $\mathrm{C}: 2.65 \pm 1.05$ \\
\hline \multirow{2}{*}{ Cha 2016 [15] } & \multirow{2}{*}{ Korea } & \multirow{2}{*}{ CKD stages 3 or 4} & I: AST-120 6 g/day & \multirow{2}{*}{36 months } & I: $272(66.9)$ & I: $56.7 \pm 13.3$ & I: $2.82 \pm 0.66$ \\
\hline & & & C: Placebo + standard care & & C: 266 (68.0) & C: $56.8 \pm 13.2$ & $\mathrm{C}: 2.84 \pm 0.70$ \\
\hline Marier 2006 [16] & USA & $1.5 \leq \mathrm{sCr} \leq 6.0 \mathrm{mg} / \mathrm{dL}$ & $\begin{array}{l}\text { I: AST-120 9 g/day } \\
\text { C: Placebo }\end{array}$ & $\begin{array}{c}7 \text { days } \\
\text { (Washout: } 9 \text { days) }\end{array}$ & $\begin{array}{l}\text { I: } 20 \\
\text { C: } 20\end{array}$ & 58 & $\begin{array}{l}\text { I: } 2.36 \pm 1.07 \\
\text { C: NA }\end{array}$ \\
\hline \multirow[t]{3}{*}{ Owada 1997 [17] } & \multirow[t]{3}{*}{ Japan } & \multirow[t]{2}{*}{$\mathrm{CKD}(\mathrm{sCr} 3-8.6 \mathrm{mg} / \mathrm{dL})$} & $\begin{array}{c}\text { I: AST-120 } 6 \mathrm{~g} / \text { day + LPD } \\
(0.6 \mathrm{~g} / \mathrm{kg})\end{array}$ & \multirow[t]{2}{*}{ 12-24 months } & I: 13 & \multirow{2}{*}{ NA } & I: $5.75 \pm 0.99$ \\
\hline & & & C: LPD $(0.6 \mathrm{~g} / \mathrm{kg})$ & & C: 13 & & $\mathrm{C}: 4.77 \pm 1.50$ \\
\hline & & \multirow{4}{*}{$\mathrm{sCr} 3-6 \mathrm{mg} / \mathrm{dL}$} & $\mathrm{I}_{1}:$ AST-120 $9 \mathrm{~g} /$ day & \multirow{4}{*}{12 weeks } & $\mathrm{I}_{1}: 39(76.9)$ & $I_{1}: 69.3 \pm 13.93$ & $\mathrm{I}_{1}: 4.33 \pm 0.87$ \\
\hline \multirow{3}{*}{ Schulman 2006 [18] } & \multirow{3}{*}{ USA } & & $\mathrm{I}_{2}:$ AST-120 $6.3 \mathrm{~g} /$ day & & $\mathrm{I}_{2}: 40(55.0)$ & $\mathrm{I}_{2}: 66.3 \pm 10.24$ & $\mathrm{I}_{2}: 4.47 \pm 0.89$ \\
\hline & & & $\mathrm{I}_{3}:$ AST-120 $2.7 \mathrm{~g} /$ day & & $\mathrm{I}_{3}: 39(76.9)$ & $\mathrm{I}_{3}: 59.6 \pm 13.83$ & $\mathrm{I}_{3}: 4.35 \pm 0.97$ \\
\hline & & & C: Placebo & & C: $39(64.1)$ & C: $63.1 \pm 12.94$ & $\mathrm{C}: 4.58 \pm 1.04$ \\
\hline \multirow{2}{*}{$\begin{array}{c}\text { Schulman } 2015 \text { [19] } \\
\text { EPPIC-1 }\end{array}$} & USA, Latin & \multirow{2}{*}{ CKD stages $3-5$} & I: AST-120 $9 \mathrm{~g} /$ day & I: $91.0 \pm 50.3$ weeks & I: 500 (61.8) & I: $56.3 \pm 14.9$ & I: $3.09 \pm 0.88$ \\
\hline & America, Europe & & C: Placebo & C: $92.6 \pm 52.6$ weeks & C: 502 (79.9) & C: $55.6 \pm 14.9$ & $\mathrm{C}: 3.10 \pm 0.84$ \\
\hline \multirow{2}{*}{$\begin{array}{l}\text { Schulman } 2015 \text { [19] } \\
\text { EPPIC-2 }\end{array}$} & USA, Latin & \multirow{2}{*}{ CKD stages $3-5$} & I: AST-120 $9 \mathrm{~g} /$ day & I: $94.1 \pm 49.9$ weeks & I: 500 (54.6) & I: $54.4 \pm 15.5$ & I: $3.06 \pm 0.87$ \\
\hline & America, Europe & & C: Placebo & C: $87.8 \pm 50.6$ weeks & C: 507 (55.5) & C: $55.5 \pm 14.6$ & $\mathrm{C}: 3.18 \pm 0.90$ \\
\hline \multirow[t]{2}{*}{ Wu 2014 [20] } & \multirow[t]{2}{*}{ Taiwan } & CKD stage 5 & $\begin{array}{c}\text { I: AST-120 } 6 \mathrm{~g} / \text { day + Mircera } \\
1.2 \mathrm{mcg} / \mathrm{kg} \mathrm{Q} 4 \mathrm{~W}\end{array}$ & \multirow{2}{*}{$\begin{array}{c}12 \text { weeks } \\
\text { (Washout: } 4 \text { weeks) }\end{array}$} & 51 (31.4) ITT & \multirow[t]{2}{*}{$61.26 \pm 11.49$} & I: $5.48 \pm 2.31$ \\
\hline & & $\mathrm{Hb}<10 \mathrm{~g} / \mathrm{dL}$ & C: Mircera* $1.2 \mathrm{mcg} / \mathrm{kg}$ Q $4 \mathrm{~W}$ & & 40 (35) PP & & $C: 5.14 \pm 2.64$ \\
\hline \multirow[t]{2}{*}{ Yorioka 2008 [21] } & \multirow[t]{2}{*}{ Japan } & $\mathrm{sCr} 1.5-5.0$ & $\begin{array}{l}\text { I: AST-120 } 6 \text { g/day + } \\
\text { conventional }\end{array}$ & \multirow[t]{2}{*}{12 months } & $\mathrm{I}: 15$ (73.3) & I: $61.7 \pm 12.6$ & I: $2.4 \pm 0.8$ \\
\hline & & eGFR 15-60 & $\begin{array}{c}\text { C: Conventional } \\
\text { (LPD } 0.8 \mathrm{~g} / \mathrm{kg} \text { and RASi) }\end{array}$ & & C:13 (58.5) & C: $59.7 \pm 8.9$ & C: $2.7 \pm 0.8$ \\
\hline
\end{tabular}

Abbreviations: C—Comparison; CKD—Chronic kidney disease; I—Intervention; ITT—Intention to treat; LPD—Low-protein diet; PP—Per protocol; RASi—Renin-angiotensin system inhibitor; $\mathrm{s} C r-$ serum creatinine. * Methoxy polyethylene glycol-epoetin beta (MIRCERA, Roche). 


\subsubsection{Study Quality}

The risk of bias assessment is shown in Figure 2. Six RCTs clearly documented the randomization process $[14,15,18-20]$, and four RCTs provided detailed descriptions of allocation concealment $[15,18,19]$. An open-label design was used in $44.4 \%$ of the included studies $[14,15,20,21]$, which could have introduced investigator or subject bias in the reporting of adverse effects. However, the primary outcomes were all laboratory values and were therefore unlikely to be affected by a lack of blinding. Two RCTs were considered to be at a high risk of attrition bias due to per-protocol analyses or differences in the proportion of incomplete outcome data across groups [14,15]. An RCT was considered to be at high risk of other bias if the sample size calculation differed from the real data [14]. Additionally, RCTs with small sample sizes were considered to have a high risk of other bias $[16,17,21]$.

(A)

\begin{tabular}{|c|c|c|c|c|c|c|c|c|c|}
\hline 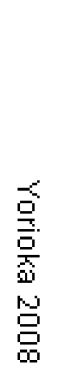 & $\begin{array}{l}\stackrel{5}{\mathrm{~B}} \\
\stackrel{\mathrm{G}}{\mathrm{g}}\end{array}$ & 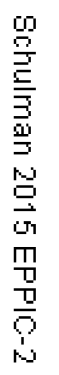 & 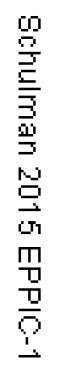 & 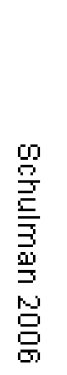 & 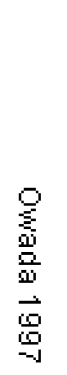 & 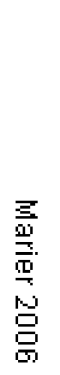 & $\begin{array}{l}\frac{9}{\vec{\Xi}} \\
\mathrm{G} \\
\mathrm{G}\end{array}$ & 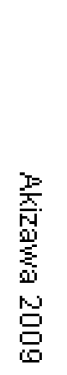 & \\
\hline$\cdot$ & $\odot$ & + & $\odot$ & $\odot$ & $\sim$ & $-\omega$ & $\odot$ & $\odot$ & Random sequence generation (selection bias) \\
\hline$\cdot$ & 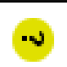 & + & + & + & 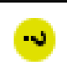 & $\cdot$ & + & 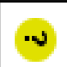 & Allocation concealment (selection bias) \\
\hline+ & + & + & $\odot$ & + & $\odot$ & + & $\odot$ & $\odot$ & Blinding of participants and personnel (performance bias) \\
\hline$\odot$ & + & + & $\odot$ & + & $\odot$ & + & $\odot$ & $\odot$ & Blinding of outcome assessment (detection bias) \\
\hline+ & $\omega$ & + & + & + & + & $\cdot$ & (1) & (1) & Incomplete outcome data (attrition bias) \\
\hline+ & + & + & $\odot$ & + & $\odot$ & -4 & $\odot$ & + & Selective reporting (reporting bias) \\
\hline (1) & $\odot$ & $\cdot$ & $\odot$ & $\odot$ & (1) & 8 & $\odot$ & (1) & Other bias \\
\hline
\end{tabular}

(B)

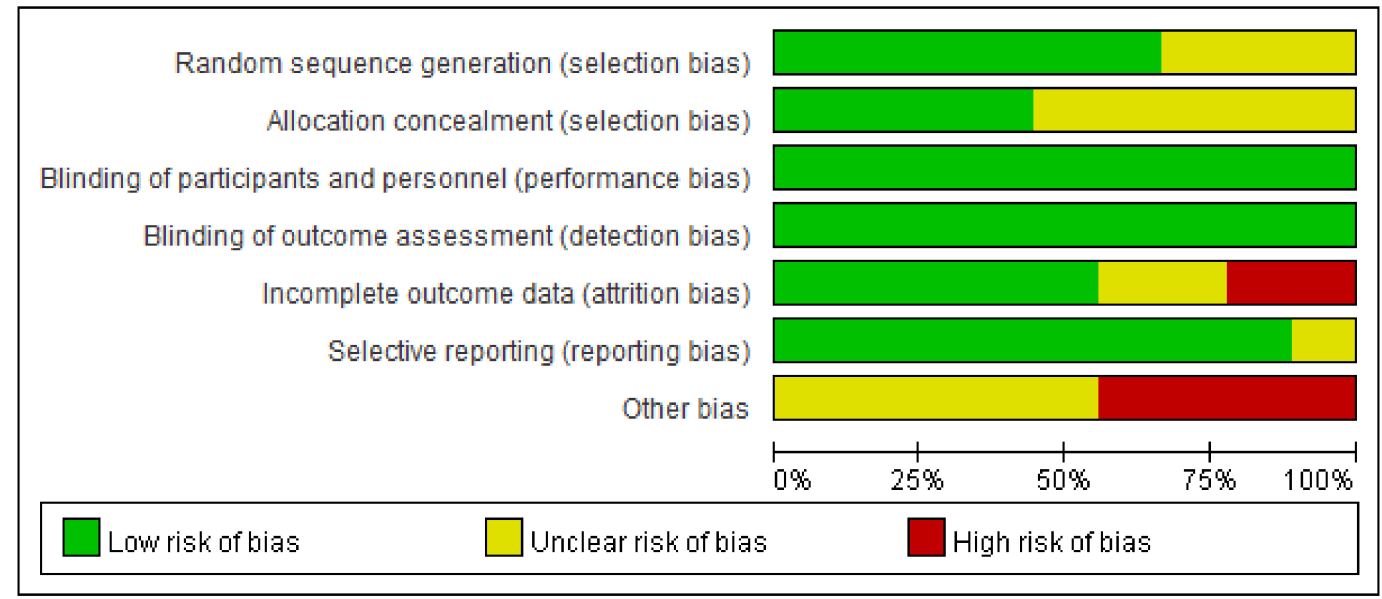

Figure 2. Risk of bias. (A) Risk of bias summary; (B) Risk of bias graph. 


\subsubsection{Publication Bias}

We did not assess the publication bias of the nine studies using the funnel plot asymmetry test because the test is unable distinguish chance from actual asymmetry when fewer than 10 studies are tested.

\subsubsection{Primary Outcomes}

\section{Composite of Renal Outcomes}

The meta-analysis for the composite of renal outcomes included six trials [14,15,19-21] with a total of 3116 participants (Figure 3A). Using a fixed-effect model, we found that the RR of the composite of renal outcomes was 0.97 (95\% CI: 0.88-1.07; heterogeneity $\mathrm{I}^{2}: 0 \%, p=0.9$ ). Thus, our meta-analysis revealed that the AST-120 groups did not significantly differ from placebo and conventional treatment groups. We also determined that the RR of the composite of renal outcomes computed in the sensitivity analysis (after excluding crossover trials) was the same as our main result.

A

\begin{tabular}{|c|c|c|c|c|c|c|c|}
\hline Study or Subgroup & $\begin{array}{l}\text { AST-12 } \\
\text { Events }\end{array}$ & 20 & $\begin{array}{l}\text { Contr } \\
\text { Events }\end{array}$ & $\begin{array}{l}\text { ol } \\
\text { Total }\end{array}$ & Weight & $\begin{array}{c}\text { Risk Ratio } \\
\text { M-H,Fixed, } 95 \% \mathrm{Cl}\end{array}$ & $\begin{array}{c}\text { Risk Ratio } \\
\text { M-H,Fixed, } 95 \% \mathrm{Cl}\end{array}$ \\
\hline Akizawa 2009 & 39 & 231 & 41 & 229 & $8.1 \%$ & $0.94[0.63,1.40]$ & \\
\hline Cha 2016 & 100 & 272 & 100 & 266 & $20.0 \%$ & $0.98[0.79,1.22]$ & \\
\hline Schulman 2015 EPPIC-1 & 178 & 500 & 177 & 502 & $34.9 \%$ & $1.01[0.85,1.19]$ & \\
\hline Schulman 2015 EPPIC-2 & 172 & 500 & 183 & 497 & $36.3 \%$ & $0.93[0.79,1.10]$ & \\
\hline Wu 2014 & 4 & 47 & 2 & 44 & $0.4 \%$ & $1.87[0.36,9.72]$ & \\
\hline Yorioka 2008 & 0 & 15 & 1 & 13 & $0.3 \%$ & $0.29[0.01,6.60]$ & \\
\hline Total $(95 \% \mathrm{Cl})$ & & 1565 & & 1551 & $100.0 \%$ & $0.97[0.88,1.07]$ & \\
\hline Total events & 493 & & 504 & & & & \\
\hline $\begin{array}{l}\text { Heterogeneity: } \mathrm{Chi}^{2}=1.62 \text {, } \\
\text { Test for overall effect: } \mathrm{Z}=\end{array}$ & $\begin{array}{l}\text { df }=5(P= \\
56(P=0\end{array}$ & $\begin{array}{l}=0.90) \text {; } \\
.58)\end{array}$ & $I^{2}=0 \%$ & & & & 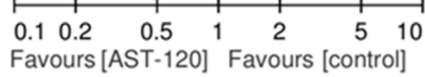 \\
\hline
\end{tabular}

B

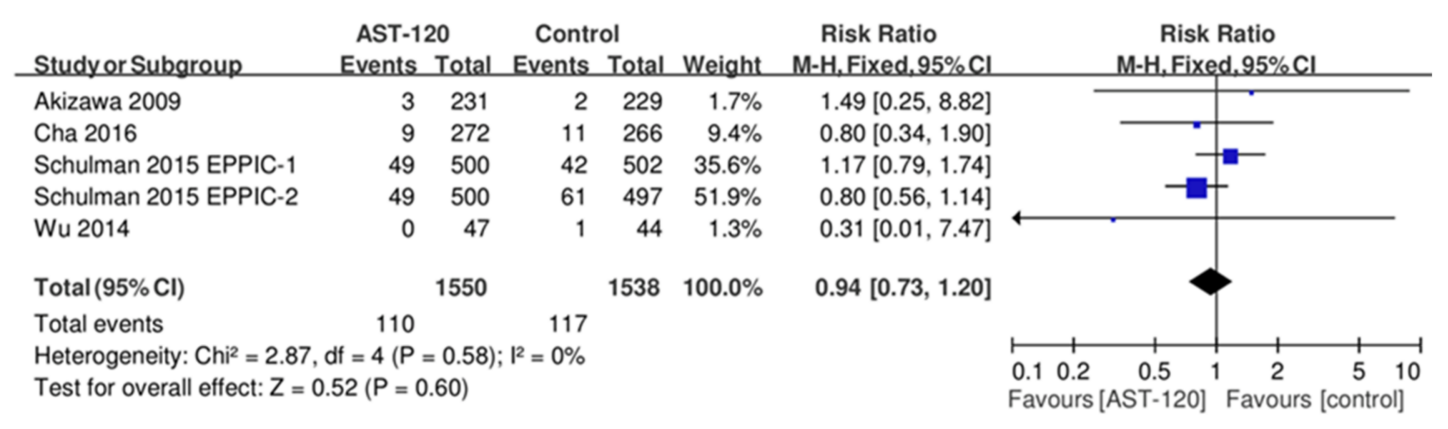

$\mathrm{C}$

\begin{tabular}{|c|c|c|c|c|c|c|c|c|c|c|}
\hline \multirow[b]{2}{*}{ Study or Subgroup } & \multicolumn{2}{|c|}{ AST-120 } & \multicolumn{3}{|r|}{ Control } & & & \multirow{2}{*}{$\begin{array}{l}\text { Mean Difference } \\
\text { IV,Random, } 95 \% \mathrm{Cl}\end{array}$} & \multirow{2}{*}{\multicolumn{2}{|c|}{$\begin{array}{c}\text { Mean Difference } \\
\text { IV.Random, } 95 \% \mathrm{Cl}\end{array}$}} \\
\hline & Mean & SD & Total & Mean & SD & Total & Weight & & & \\
\hline Cha 2016 & 0.0745 & 0.5621 & 272 & 0.2565 & 1.17607 & 266 & $31.6 \%$ & $-0.18[-0.34,-0.03]$ & & \\
\hline Owada 1997 & -0.55 & 0.635 & 13 & 0 & 0.513 & 13 & $11.4 \%$ & $-0.55[-0.99,-0.11]$ & & \\
\hline Schulman 2006 & -0.1663 & 0.351 & 116 & -0.027 & 0.371 & 38 & $33.8 \%$ & $-0.14[-0.27,-0.01]$ & & - \\
\hline Wu 2014 & -0.382 & 0.641 & 40 & 0.112 & 0.465 & 40 & $23.1 \%$ & $-0.49[-0.74,-0.25]$ & & \\
\hline Total $(95 \% \mathrm{Cl})$ & & & 441 & & & 357 & $100.0 \%$ & $-0.28[-0.46,-0.11]$ & & \\
\hline $\begin{array}{l}\text { Heterogeneity: } \mathrm{Tau}^{2} \\
\text { Test for overall effec }\end{array}$ & $\begin{array}{l}0.02 ; \mathrm{Chi}^{2} \\
\mathrm{Z}=3.14\end{array}$ & $\begin{array}{l}=8.53 \\
P=0.00\end{array}$ & $\begin{array}{l}\text { df }=3(\mathrm{~F} \\
\text { 2) }\end{array}$ & $P=0.04)$ & $; 1^{2}=65 \%$ & & & & $\begin{array}{ll}-2 & -1 \\
\text { Favours [AST-120] }\end{array}$ & $\left.0 \begin{array}{c}1 \\
0\end{array}\right]$ Favours [control] \\
\hline
\end{tabular}

Figure 3. Result of primary outcomes for comparison between AST-120 and control groups. (A) Composite of renal outcome; (B) All-cause mortality; (C) Change in serum indoxyl sulfate levels.

All-Cause Mortality

Five studies $[14,15,19,20]$ with a total of 3088 participants provided data on all-cause mortality (Figure 3B). We used a fixed-effect model to estimate the RR for this outcome. The RR of all-cause 
mortality was 0.94 (95\% CI: 0.73-1.20) with low heterogeneity ( $\left.\mathrm{I}^{2}: 0 \%, p=0.58\right)$. Thus, our meta-analysis also showed no significant difference in all-cause mortality between the AST-120 groups and placebo or conventional treatment groups. The RR of all-cause mortality computed in the sensitivity analysis (after excluding the crossover trials) was the same as the main result.

\section{Change in Serum IS Levels}

In a meta-analysis of four studies, which included a total of 798 participants, the weighted mean change in serum IS levels from baseline to the end of the study was -0.28 (95\% CI: -0.46 to -0.11 ) in patients treated with AST-120 compared with those receiving placebo or conventional treatment (Figure 3C). We assumed that the treatment effect was heterogeneous across studies, so we used a random-effects model to estimate the weighted mean change in serum IS levels (heterogeneity $\mathrm{I}^{2}$ : $65 \%, p=0.04)$. In the sensitivity analysis, after the exclusion of crossover trials, the weighted mean change in serum IS from baseline to the end of the study was -0.19 ( $95 \% \mathrm{CI}:-0.33$ to -0.06 ) in patients treated with AST-120 compared with those who received placebo or conventional treatment.

\subsubsection{Secondary Outcomes}

In this meta-analysis, the risks of constipation, diarrhea, and gastrointestinal disorders did not differ significantly between patients treated with AST-120 and those treated with placebo or conventional drugs. Compared with individuals treated with placebo or conventional drugs, the RR of dermatological events among patients treated with AST-120 was 1.57 (95\% CI: $1.20-2.05)$. Details of the comparisons between AST-120 and the placebo or conventional groups are provided in Figure 4 . The results of our sensitivity analysis, after the exclusion of crossover trials, were identical to the main result.

\section{Discussion}

The present meta-analysis included eight studies with nine RCTs, representing a total of 3349 patients with stage 3-5 CKD. The analyzed studies collectively showed that patients with CKD who received AST-120 did not register a considerable improvement in renal outcome and all-cause mortality, but AST-120 did reduce the level of serum IS. We also found that the risks of constipation, diarrhea, and gastrointestinal disorders did not differ significantly between patients treated with AST-120 and control groups; however, dermatological events were more common in patients treated with AST-120 than in those treated with placebo or conventional drugs.

CKD results in the accumulation of metabolic waste products that are normally cleared by the kidneys. Studies have demonstrated that the accumulation of uremic toxins, such as IS and p-cresyl sulfate, induces free radical production in renal tubular cells and glomerular mesangial cells [22,23], which then accelerates CKD progression [24]. Among uremic toxins, IS is the most well studied. It is formed from indole, a tryptophan metabolite, which is synthesized by intestinal bacteria and absorbed from the intestine into the blood. Once in circulation, indole may be sequentially converted to indoxyl and IS in the liver [25]. One possible mechanism that may allow AST-120 to reduce IS is that it adsorbs indole in the intestine and causes the indole to be excreted in the feces, thereby limiting the bioavailability of the IS precursor $[7,26]$.

In contrast to the findings from our meta-analysis, AST-120 has been shown to delay CKD progression in some studies, most of which have been conducted in Japan [27-29]. In a Japanese phase III trial [29], patients who received AST-120 treatment for 24 weeks were significantly more likely to show improvements in the change of reciprocal of the creatinine level compared to the placebo group ( $43 \%$ and $24 \%$ in the AST and placebo groups, respectively, $p<0.01$ ). In addition, the time to achieve the primary endpoints of the doubling of serum creatinine levels or the initiation of dialysis differed significantly between the two groups [29]. 


\begin{tabular}{|c|c|c|c|c|c|}
\hline \multirow{2}{*}{$\begin{array}{l}\text { A } \\
\text { Study or Subaroup }\end{array}$} & \multicolumn{2}{|c|}{ AST-120 } & \multicolumn{2}{|c|}{ Control } & \multirow[b]{2}{*}{ Weight } \\
\hline & Events & Total & Events & Total & \\
\hline Akizawa 2009 & 12 & 237 & 0 & 236 & $4.8 \%$ \\
\hline Marier 2006 & 3 & 20 & 0 & 20 & $4.6 \%$ \\
\hline Schulman 2006 & 9 & 118 & 5 & 39 & $18.2 \%$ \\
\hline Schulman 2015 EPPIC-1 & 25 & 507 & 21 & 509 & $26.1 \%$ \\
\hline Schulman 2015 EPPIC-2 & 25 & 507 & 19 & 505 & $25.8 \%$ \\
\hline Wu 2014 & 20 & 47 & 5 & 44 & $20.5 \%$ \\
\hline Total $(95 \% \mathrm{Cl})$ & & 1436 & & 1353 & $100.0 \%$ \\
\hline Total events & 94 & & 50 & & \\
\hline
\end{tabular}

Heterogeneity: $\mathrm{Tau}^{2}=0.37 ; \mathrm{Chi}^{2}=13.49, \mathrm{df}=5(\mathrm{P}=0.02) ; \mathrm{l}^{2}=63 \%$ Test for overall effect: $Z=1.57(P=0.12)$

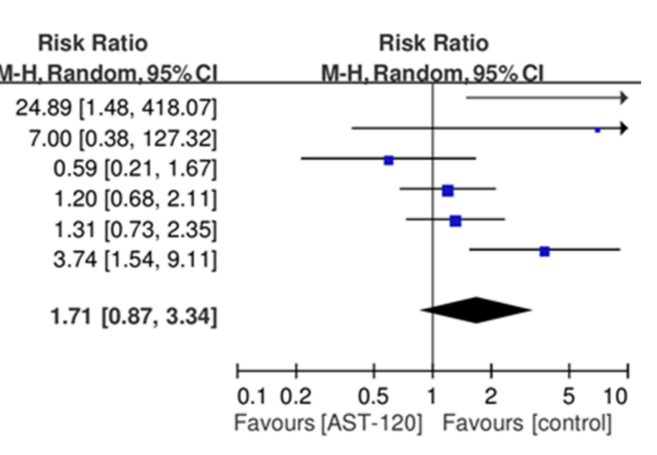

B

\section{C}

\begin{tabular}{|c|c|c|c|c|c|c|c|c|}
\hline Study or Subgroup & \multicolumn{2}{|c|}{$\begin{array}{l}\text { AST-120 } \\
\text { Events Total }\end{array}$} & \multicolumn{2}{|c|}{$\begin{array}{l}\text { Control } \\
\text { Events Total }\end{array}$} & Weight & \multirow{2}{*}{$\begin{array}{c}\text { Risk Ratio } \\
\text { M-H, Random, } 95 \% \mathrm{Cl}\end{array}$} & \multicolumn{2}{|c|}{$\begin{array}{c}\text { Risk Ratio } \\
\mathrm{M}-\mathrm{H}, \text { Random, } 95 \% \mathrm{Cl}\end{array}$} \\
\hline Akizawa 2009 & 10 & 237 & 1 & 236 & $3.3 \%$ & & & \\
\hline Cha 2016 & 293 & 295 & 204 & 284 & $32.6 \%$ & $1.38[1.28,1.49]$ & & - \\
\hline Schulman 2006 & 21 & 118 & 6 & 39 & $13.4 \%$ & $1.16[0.50,2.66]$ & & \\
\hline Schulman 2015 EPPIC-1 & 35 & 507 & 42 & 509 & $23.6 \%$ & $0.84[0.54,1.29]$ & & \\
\hline Schulman 2015 EPPIC-2 & 47 & 507 & 52 & 505 & $25.4 \%$ & $0.90[0.62,1.31]$ & & \\
\hline Wu 2014 & 2 & 47 & 0 & 44 & $1.6 \%$ & $4.69[0.23,95.00]$ & & \\
\hline Total $(95 \% \mathrm{Cl})$ & & 1711 & & 1617 & $100.0 \%$ & $1.17[0.79,1.74]$ & & \\
\hline Total events & 408 & & 305 & & & & & \\
\hline $\begin{array}{l}\text { Heterogeneity: } \text { Tau }^{2}=0.1 \\
\text { Test for overall effect: } Z=\end{array}$ & $\begin{array}{l}\mathrm{Chi}^{2}=17 \\
79(\mathrm{P}=0\end{array}$ & $\begin{array}{l}.77, \mathrm{df}= \\
.43)\end{array}$ & $=5(P=0$ & $.003) ; 1$ & $L^{2}=72 \%$ & & 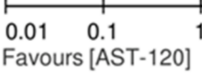 & $\begin{array}{ccc}1 & 10 & 100 \\
\text { Favours [control] }\end{array}$ \\
\hline
\end{tabular}

$\mathrm{D}$

\begin{tabular}{|c|c|c|c|c|c|c|c|c|}
\hline Study or Subgroup & \multicolumn{2}{|c|}{ AST-120 } & \multicolumn{2}{|c|}{ Control } & Weight & $\begin{array}{c}\text { Risk Ratio } \\
\text { M-H,Fixed, } 95 \% \mathrm{Cl}\end{array}$ & \multicolumn{2}{|c|}{$\begin{array}{c}\text { Risk Ratio } \\
\text { M-H,Fixed, } 95 \% \mathrm{Cl}\end{array}$} \\
\hline Akizawa 2009 & 6 & 237 & 0 & 236 & $0.7 \%$ & $12.95[0.73,228.50]$ & & \\
\hline Cha 2016 & 85 & 295 & 54 & 284 & $75.0 \%$ & $1.52[1.12,2.04]$ & & \\
\hline Schulman 2006 & 4 & 118 & 0 & 39 & $1.0 \%$ & $3.03[0.17,54.96]$ & & \\
\hline Schulman 2015 EPPIC-1 & 8 & 507 & 5 & 509 & $6.8 \%$ & $1.61[0.53,4.88]$ & & \\
\hline Schulman 2015 EPPIC-2 & 13 & 507 & 11 & 505 & $15.0 \%$ & $1.18[0.53,2.60]$ & & \\
\hline Wu 2014 & 2 & 47 & 1 & 44 & $1.4 \%$ & $1.87[0.18,19.93]$ & & \\
\hline Total $(95 \% \mathrm{Cl})$ & & 1711 & & 1617 & $100.0 \%$ & $1.57[1.20,2.05]$ & & \\
\hline Total events & 118 & & 71 & & & & & \\
\hline $\begin{array}{l}\text { Heterogeneity: } \mathrm{Chi}^{2}=2.8 \\
\text { Test for overall effect: } \mathrm{Z}=\end{array}$ & $\begin{array}{l}\text { df }=5(P= \\
30(P=0\end{array}$ & $\begin{array}{l}=0.72) \text {; } \\
.0010)\end{array}$ & $I^{2}=0 \%$ & & & & $\begin{array}{ccc} & 1 & 1 \\
0.1 & 0.2 & 0.5 \\
\text { Favours } & \text { [AST-120] }\end{array}$ & $\begin{array}{lccc}1 & 2 & 5 & 10 \\
\text { Favours [control] }\end{array}$ \\
\hline
\end{tabular}

Figure 4. Result of secondary outcomes for comparison between AST-120 and control groups. (A) Constipation; (B) Diarrhea; (C) Gastrointestinal disorders; (D) Dermatological events.

The difference between our meta-analysis results and the Japanese phase III trial may have several possible explanations. First, the discrepancy may be attributable to differences between actual and estimated event curves. For example, AST-120 was not efficacious in delaying CKD progression in two randomized double-blind phase III trials (EPPIC-1 and EPPIC-2) [19]; however, in the placebo groups of these studies, the estimated median time to the primary endpoint of CKD progression 
was 124 weeks, whereas the actual mean times were 189.0 and 170.3 weeks for the EPPIC-1 and EPPIC-2 trials, respectively. The delays suggest that the controls in these studies progressed more slowly than expected. Nevertheless, post-hoc studies demonstrated that AST-120 patients with progressive CKD [30] and higher compliance [31] potentially delay the time to the primary end point. Moreover, the eGFR level was more stable in the AST-120 group, especially in patients with diabetic nephropathy [32].

Second, regional differences in the decision to initiate dialysis could have contributed to the differences in renal outcomes. Patients in Western countries typically had higher mean eGFR values at the initiation of dialysis than did patients in Asian countries [33]. This difference may reflect differing evaluations of disease progression between Western and Asian practitioners. Third, variations in diet and nutritional status between countries may have affected the results. Despite the unconfirmed role of nutrition in CKD, some reviews have suggested that unrestricted protein intake may increase the risk of disease progression [34]. Thus, our meta-analysis may have failed to identify the clinical benefits of AST-120 based on technical or regional issues that influenced the results of phase III trials.

According to previous publications, we expected that AST-120 should significantly reduce serum IS levels [18]. In a multicenter RCT on patients with moderate to severe CKD, 12 weeks after receiving AST-120 treatment, patients treated with $9.0 \mathrm{~g}$ and $2.7 \mathrm{~g}$ of AST- 120 showed $39.3 \%$ and $2.6 \%$ reductions, respectively, in serum IS levels [18]. The theoretical maximal amount of creatinine that can be absorbed in the gastrointestinal tract after the administration of $9.0 \mathrm{~g} /$ day of AST-120 is approximately $10 \mathrm{mg} / \mathrm{g}[34,35]$. In our meta-analysis, the daily AST-120 dosage in the included studies ranged from 2.7 to $9.0 \mathrm{~g}$, and we saw reduced serum IS levels, which is consistent with the findings of previous studies [35].

Decreasing serum IS levels may be beneficial for cardiovascular outcomes [36-38]. Barreto et al. demonstrated that serum IS levels were positively and significantly associated with aortic calcification and pulse wave velocity [36]. Sato et al also reported that in patients with a higher IS level, there was a higher proportion of left ventricular dysfunction [39]. In previous studies, IS has been implicated in the pathogenesis of at least six phenotypes of cardiovascular disease [40], including atherosclerosis [37], arteriosclerosis [41], congestive heart failure [38], arrhythmia [42,43], peripheral arterial disease [44], and vascular thrombosis [45]. Several studies revealed that high serum IS levels independently predicted overall mortality $[36,46]$. However, in our study, all-cause mortality was not correlated with serum IS level.

Because AST-120 is not absorbed into the bloodstream or tissue, it is not expected to exert major systemic effects $[6,18]$. The most commonly reported treatment-related adverse events for AST-120 include mild to moderate constipation, diarrhea, and flatulence, which are all effects on the gastrointestinal system $[16,18]$. Several studies have also investigated relatively rare adverse events, such as pruritus, poor appetite, and nutritional problems; in most previous studies and reviews, the incidence of non-gastrointestinal adverse events did not differ significantly between the AST-120 and placebo groups $[15,18,19]$.

Compared with previous meta-analyses, our study has several strengths. First, all included RCTs were critically assessed, and the overall risk of bias was lower than that reported in previous meta-analyses. Second, we considered all relevant outcomes (namely all-cause mortality, change in serum IS levels, and incidence of adverse gastrointestinal and dermatological effects). Third, we comprehensively searched multiple databases in all languages; therefore, we are unlikely to have missed a substantial number of relevant studies.

Our study also has several limitations. First, the progression rate for CKD is usually estimated from the slope of a plot with the reciprocal of creatinine versus time. However, the actual curves may differ considerably from estimated curves. Second, differences in population characteristics, region, diet and nutrition status, AST-120 dosage, renal function status, and concurrent medications in the included studies could have contributed to the observed heterogeneity in results. Third, the length of follow-up varied across studies, resulting in potentially significant variations in the incidence of adverse effects. 


\section{Conclusions}

Although AST-120-treated patients had reduced serum IS levels, they did not exhibit considerable improvements in renal outcome and all-cause mortality. Except for dermatological events, the incidences of adverse events in patients treated with AST-120 were similar to those in placebo groups. Because of limitations and bias in previous studies, possible clinical benefits, such as the alleviation of uremic symptoms, were not assessed in our study. Additional large-scale RCTs with longer follow-up durations and standardized outcomes are still necessary to clarify the clinical efficacy of AST-120.

Author Contributions: Conceptualization, Y.-C.C. and M.-Y.W.; data curation, Y.-C.C. and M.-Y.W.; formal analysis, Y.-C.C. and T.-T.C.; funding acquisition, Y.-C.C., W.-C.S., W.-C.C., and M.-S.W.; investigation, Y.-C.C., M.-Y.W., and T.-T.C.; methodology, Y.-C.C., M.-Y.W., and T.-T.C.; project administration, M.-Y.W.; resources, M.-Y.W.; software, Y.-C.C. and T.-T.C.; supervision, W.-C.S., W.-C.C., and M.-S.W.; validation, M.-Y.W., P.-J.H., W.-C.C., and M.-S.W.; visualization, Y.-C.C., M.-Y.W., P.-J.H., and T.-T.C.; writing-original draft, Y.-C.C., M.-Y.W., P.-J.H., and T.-T.C.; writing-review and editing, W.-C.S., W.-C.C., and M.-S.W.

Funding: This study was supported by grants from the Taipei Medical University (103TMU-SHH-14), Taipei Medical University (106-5807-001-400; Yusuke Nakamura Chair Professorship), and from the Shuang Ho Hospital (107HCP-05).

Conflicts of Interest: The authors declare no conflict of interest.

\section{References}

1. Hill, N.R.; Fatoba, S.T.; Oke, J.L.; Hirst, J.A.; O'Callaghan, C.A.; Lasserson, D.S.; Hobbs, F.D. Global Prevalence of Chronic Kidney Disease-A Systematic Review and Meta-Analysis. PLoS ONE 2016, 11, e0158765. [CrossRef] [PubMed]

2. Chronic Kidney disease Prognosis Consortium; Matsushita, K.; van der Velde, M.; Astor, B.C.; Woodward, M.; Levey, A.S.; de Jong, P.E.; Coresh, J.; Gansevoort, R.T. Association of estimated glomerular filtration rate and albuminuria with all-cause and cardiovascular mortality in general population cohorts: A collaborative meta-analysis. Lancet 2010, 375, 2073-2081. [PubMed]

3. Liyanage, T.; Ninomiya, T.; Jha, V.; Neal, B.; Patrice, H.M.; Okpechi, I.; Zhao, M.H.; Lv, J.; Garg, A.X.; Knight, J.; et al. Worldwide access to treatment for end-stage kidney disease: A systematic review. Lancet 2015, 385, 1975-1982. [CrossRef]

4. Nelson, R.G.; Tuttle, K.R.; Bilous, R.W.; Gonzalez-Campoy, J.M.; Mauer, M.; Molitch, M.E.; Sharma, K.; Fradkin, J.E.; Narva, A.S.; Wilt, T.J.; et al. KDOQI clinical practice guideline for diabetes and CKD: 2012 update. Am. J. Kidney Dis. 2012, 60, 850-886.

5. Kidney Disease Outcomes Quality Initiative (K/DOQI). K/DOQI clinical practice guidelines on hypertension and antihypertensive agents in chronic kidney disease. Am. J. Kidney Dis. 2004, 43 (Supp. 1), S1-290.

6. Koide, K.; Sano, M.; Takeda, F.; Momose, T.; Koshikawa, S.; Akizawa, T. A study of oral adsorbent in chronic renal failure. Biomater. Artif. Cells Immobil. Biotechnol. 1991, 19, 147-166. [CrossRef]

7. Miyazaki, T.; Aoyama, I.; Ise, M.; Seo, H.; Niwa, T. An oral sorbent reduces overload of indoxyl sulphate and gene expression of TGF-beta1 in uraemic rat kidneys. Nephrol. Dial. Transpl. 2000, 15, 1773-1781. [CrossRef]

8. Nakagawa, N.; Hasebe, N.; Sumitomo, K.; Fujino, T.; Fukuzawa, J.; Hirayama, T.; Kikuchi, K. An oral adsorbent, AST-120. suppresses oxidative stress in uremic rates. Am. J. Nephrol. 2006, 26, 455-461. [CrossRef]

9. Okada, K.; Matsumoto, K.; Takahashi, S. Uremic toxins adsorbed by AST-120 promote tubular hypertrophy and interstitial fibrosis in nephrectomized rates. Kidney Blood Press. Res. 2005, 28, 8-13. [CrossRef]

10. Okada, K.; Okawa, E.; Shibahara, H.; Maruyama, T.; Maruyama, N.; Matsumoto, K.; Takahashi, S. Combination therapy with angiotensin-converting enzyme inhibitor and oral adsorbent of uremic toxins can delay the appearance of glomerular sclerosis and interstitial fibrosis in established renal failure. Kidney Blood Press. Res. 2004, 27, 218-225. [CrossRef]

11. Higgins, J.P.T.; Altman, D.G.; Sterne, J.A.C. Chapter 8: Assessing risk of bias in included studies. In Cochrane Handbook for Systematic Reviews of Interventions; John Wiley \& Sons Ltd.: Chichester, UK, 2011.

12. Higgins, J.P.; Thompson, S.G.; Deeks, J.J.; Altman, D.G. Measuring inconsistency in meta-analyses. BMJ. 2003, 327, 557-560. [CrossRef] [PubMed]

13. Elbourne, D.R.; Altman, D.G.; Higgins, J.P.; Curtin, F.; Worthington, H.V.; Vail, A. Meta-analyses involving cross-over trials: Methodological issues. Int. J. Epidemiol. 2002, 31, 140-149. [CrossRef] [PubMed] 
14. Akizawa, T.; Asano, Y.; Morita, S.; Wakita, T.; Onishi, Y.; Fukuhara, S.; Gejyo, F.; Matsuo, S.; Yorioka, N.; Kurokawa, K.; et al. Effect of a carbonaceous oral adsorbent on the progression of CKD: A multicenter, randomized, controlled trial. Am. J. Kidney Dis. 2009, 54, 459-467. [CrossRef] [PubMed]

15. Cha, R.H.; Kang, S.W.; Park, C.W.; Cha, D.R.; Na, K.Y.; Kim, S.G.; Yoon, S.A.; Han, S.Y.; Chang, J.H.; Park, S.K.; et al. A Randomized, Controlled Trial of Oral Intestinal Sorbent AST-120 on Renal Function Deterioration in Patients with Advanced Renal Dysfunction. Clin. J. Am. Soc. Nephrol. 2016, 11, 559-567. [CrossRef] [PubMed]

16. Marier, J.F.; Lee, J.; Kambhampati, S.R.; Galitz, L.; Vargas, R.; Moberly, J.; Salazar, D.E. Effect of repeated oral administrations of the oral adsorbent AST-120 on serum creatinine and other markers of renal function. A randomized controlled study in patients with chronic kidney disease. Am. J. Nephrol. 2006, 26, 136-141. [CrossRef]

17. Owada, A.; Nakao, M.; Koike, J.; Ujiie, K.; Tomita, K.; Shiigai, T. Effects of oral adsorbent AST-120 on the progression of chronic renal failure: A randomized controlled study. Kidney Int. Suppl. 1997, 63, S188-S190.

18. Schulman, G.; Agarwal, R.; Acharya, M.; Berl, T.; Blumenthal, S.; Kopyt, N. A multicenter, randomized, double-blind, placebo-controlled, dose-ranging study of AST-120 (Kremezin) in patients with moderate to severe CKD. Am. J. Kidney Dis. 2006, 47, 565-577. [CrossRef]

19. Schulman, G.; Berl, T.; Beck, G.J.; Remuzzi, G.; Ritz, E.; Arita, K.; Kato, A.; Shimizu, M. Randomized placebo-controlled EPPIC trials of AST-120 in CKD. J. Am. Soc. Nephrol. 2015, 26, 1732-1746. [CrossRef]

20. Wu, I.W.; Hsu, K.H.; Sun, C.Y.; Tsai, C.J.; Wu, M.S.; Lee, C.C. Oral adsorbent AST-120 potentiates the effect of erythropoietin-stimulating agents on Stage 5 chronic kidney disease patients: A randomized crossover study. Nephrol. Dial. Transpl. 2014, 29, 1719-1727. [CrossRef]

21. Yorioka, N.; Kiribayashi, K.; Naito, T.; Ogata, S.; Yokoyama, Y.; Kyuden, Y.; Ogawa, T.; Wada, K.; Hayashi, K.; Hirabayashi, A. An oral adsorbent, AST-120, combined with a low-protein diet and RAS blocker, for chronic kidney disease. J. Nephrol. 2008, 21, 213-220.

22. Motojima, M.; Hosokawa, A.; Yamato, H.; Muraki, T.; Yoshioka, T. Uremic toxins of organic anions up-regulate PAI-1 expression by induction of NF-kappaB and free radical in proximal tubular cells. Kidney Int. 2003, 63, 1671-1680. [CrossRef] [PubMed]

23. Gelasco, A.K.; Raymond, J.R. Indoxyl sulfate induces complex redox alterations in mesangial cells. Am. J. Physiol. Ren. Physiol. 2006, 290, F1551-F1558. [CrossRef] [PubMed]

24. Vanholder, R.; Schepers, E.; Pletinck, A.; Nagler, E.V.; Glorieux, G. The uremic toxicity of indosyl sulfate and p-cresyl sulfate: A systemic review. J. Am. Soc. Nephrol. 2014, 25, 1897-1907. [CrossRef]

25. Niwa, T. Indosyl sulfate is a nephro-vascular toxin. J. Ren. Nutr. 2010, 20 (Suppl. 5), S2-S6. [CrossRef]

26. Toyoda, S.; Kikuchi, M.; Komatsu, T.; Hori, Y.; Nakahara, S.; Kobayashi, S.; Sakai, Y.; Inoue, T.; Taguchi, I. Impact of the oral adsorbent AST-120 on oxidative stress and uremic toxins in high-risk chronic kidney disease patients. Int. J. Cardiol. 2014, 177, 705-707. [CrossRef] [PubMed]

27. Hatakeyama, S.; Yamamoto, H.; Okamoto, A.; Imanishi, K.; Tokui, N.; Okamoto, T.; Suzuki, Y.; Sugiyama, N.; Imai, A.; Kudo, S.; et al. Effect of an oral adsorbent, AST-120, on dialysis initiation and survival in patients with chronic kidney disease. Int. J. Nephrol. 2012, 2012, 376128. [CrossRef]

28. Konishi, K.; Nakano, S.; Tsuda, S.; Nakagawa, A.; Kigoshi, T.; Koya, D. AST-120 (Kremezin) initiated in early stage chronic kidney disease stunts the progression of renal dysfunction in type 2 diabetic subjects. Diabetes Res. Clin. Pract. 2008, 81, 310-315. [CrossRef]

29. Koshikawa, S.; Koide, K.; Yamane, Y. The effect of AST-120 on delaying initiation of dialysis therapy in end stage renal disease. Kidney Dial. 1992, 32, 783-794.

30. Schulman, G.; Berl, T.; Beck, G.J.; Remuzzi, G.; Ritz, E.; Shimizu, M.; Kikuchi, M.; Shobu, Y. Risk factors for progression of chronic kidney disease in the EPPIC trials and the effect of AST-120. Clin. Expe. Nephrol. 2018, 22, 299-308. [CrossRef]

31. Schulman, G.; Berl, T.; Beck, G.J.; Remuzzi, G.; Ritz, E.; Shimizu, M.; Shobu, Y.; Kikuchi, M. The effects of AST-120 on chronic kidney disease progression in the United States of America: A post hoc subgroup analysis of randomized controlled trials. BMC Nephrol. 2016, 17, 141. [CrossRef]

32. Cha, R.H.; Kang, S.W.; Park, C.W.; Cha, D.R.; Na, K.Y.; Kim, S.G.; Yoon, S.A.; Kim, S.; Han, S.Y.; Park, J.H.; et al. Sustained uremic toxin control improves renal and cardiovascular outcomes in patients with advanced renal dysfunction: Post-hoc analysis of the Kremezin Study against renal disease progression in Korea. Kidney Res. Clin. Pract. 2017, 36, 68-78. [CrossRef] [PubMed] 
33. United States Renal Data System (USRDS). USRDS 2018 Annual Data Report. Available online: http: //www.usrds.org/2018/view/v2_11.aspx (accessed on 30 June 2019).

34. Fouque, D.; Laville, M. Low protein diets for chronic kidney disease in non diabetic adults. Cochrane Database Syst. Rev. 2009, 3, CD001892. [CrossRef] [PubMed]

35. Asai, M.; Kumakura, S.; Kikuchi, M. Review of the efficacy of AST-120 (Kremezin) on renal function in chronic kidney disease patients. Ren. Fail. 2019, 41, 47-56. [CrossRef] [PubMed]

36. Barreto, F.C.; Barreto, D.V.; Liabeuf, S.; Meert, N.; Glorieux, G.; Temmar, M.; Choukroun, G.; Vanholder, R.; Massy, Z.A. European Uremic Toxin Work Group (EUTox). Serum indoxyl sulfate is associated with vascular disease and mortality in chronic kidney disease patients. Clin. J. Am. Soc. Nephrol. 2009, 4, 1551-1558. [CrossRef]

37. Tumur, Z.; Niwa, T. Indoxyl sulfate inhibits NO production and cell viability by inducing oxidative stress in vascular endothelial cells. Am. J. Nephrol. 2009, 29, 551-557. [CrossRef]

38. Lekawanvijit, S.; Kompa, A.R.; Manabe, M.; Wang, B.H.; Langham, R.G.; Nishijima, F.; Kelly, D.J.; Krum, H. Chronic kidney disease-induced cardiac fibrosis is ameliorated by reducing circulating levels of a non-dialysable uremic toxin, indoxyl sulfate. PLoS ONE 2012, 7, e41281. [CrossRef]

39. Sato, B.; Yoshikawa, D.; Ishii, H.; Suzuki, S.; Inoue, Y.; Takeshita, K.; Tanaka, M.; Kumagai, S.; Matsumoto, M.; Okumura, S.; et al. Relation of plasma indoxyl sulfate levels and estimated glomerular filtration rate to left ventricular diastolic dysfunction. Am. J. Cardiol. 2013, 111, 712-716. [CrossRef]

40. Hung, S.C.; Kuo, K.L.; Wu, C.C.; Tarng, D.C. Indoxyl sulfate: A novel cardiovascular risk factor in chronic kidney disease. J. Am. Heart Assoc. 2017, 6, e005022. [CrossRef]

41. Muteliefu, G.; Enomoto, A.; Niwa, T. Indoxyl sulfate promotes proliferation of human aortic smooth muscles by inhibiting oxidative stress. J. Ren. Nutr. 2009, 19, 29-32. [CrossRef]

42. Tang, W.H.; Wang, C.P.; Chung, F.M.; Huang, L.L.; Yu, T.H.; Hung, W.C.; Lu, L.F.; Chen, P.Y.; Luo, C.H.; Lee, K.T.; et al. Uremic retention solute indoxyl sulfate level is associated with prolonged QTc interval in early CKD patient. PLoS ONE 2015, 10, e0119545. [CrossRef]

43. Chen, W.T.; Chen, Y.C.; Hsieh, M.H.; Huang, S.Y.; Kao, Y.H.; Chen, Y.A.; Lin, Y.K.; Chen, S.A.; Chen, Y.J. The uremic toxin indoxyl sulfate increases pulmonary vein and artial arrhythmogenesis. J. Cardiovasc. Electrophysiol. 2015, 26, 203-210. [CrossRef]

44. Gondonin, B.; Cerini, C.; Dou, L.; Sallée, M.; Duval-Sabatier, A.; Pletinck, A.; Calaf, R.; Lacroix, R.; Jourde-Chiche, N.; Poitevin, S.; et al. Indolic uremic solutes increase tissue factor production in endothelial cells by the aryl hydrocarbon receptor pathway. Kidney Int. 2013, 84, 733-744. [CrossRef]

45. Hung, S.C.; Kuo, K.L.; Huang, H.L.; Lin, C.C.; Tsai, T.H.; Wang, C.H.; Chen, J.W.; Lin, S.J.; Huang, P.H.; Tarng, D.C. Indoxyl sulfate suppresses endothelial progenitor cell-mediated neovascularization. Kidney Int. 2016, 89, 574-585. [CrossRef]

46. Melamed, M.L.; Plantinga, L.; Shafi, T.; Parekh, R.; Meyer, T.W.; Hostetter, T.H.; Coresh, J.; Powe, N.R. Retained organic solutes, patients characteristics and all-cause and cardiovascular mortality in hemodialysis: Results from the retained organic solutes and clinical outcomes (ROSCO) investigators. BMC Nephrol. 2013, 14, 134. [CrossRef]

(C) 2019 by the authors. Licensee MDPI, Basel, Switzerland. This article is an open access article distributed under the terms and conditions of the Creative Commons Attribution (CC BY) license (http://creativecommons.org/licenses/by/4.0/). 